\title{
Biological oxygen demand optode analysis of coral reef-associated microbial communities exposed to algal exudates
}

Algal-derived dissolved organic matter has been hypothesized to induce mortality of reef building corals. One proposed killing mechanism is a zone of hypoxia created by rapidly growing microbes. To investigate this hypothesis, biological oxygen demand (BOD) optodes were used to quantify the change in oxygen concentrations of microbial communities following exposure to exudates generated by turf algae and crustose coralline algae (CCA). BOD optodes were embedded with microbial communities cultured from Montastraea annularis and Mussismilia hispida, and respiration was measured during exposure to turf and CCA exudates. The oxygen concentrations along the optodes were visualized with a low-cost Submersible Oxygen Optode Recorder (SOOpR) system. With this system we observed that exposure to exudates derived from turf algae stimulated higher oxygen draw down by the coral- associated bacteria than CCA exudates or seawater controls. Furthermore, in both turf and CCA exudate treatments, all microbial communities (coral- , algal-associated and pelagic) contributed significantly to the observed oxygen drawdown. This suggests that the driving factor for elevated oxygen consumption rates is the source of exudates rather than the initially introduced microbial community. Our results demonstrate that exudates from turf algae may contribute to hypoxia-induced coral stress in two different coral genera as a result of increased biological oxygen demand of the local microbial community. Additionaly, the SOOpR system developed here can be applied to measure the BOD of any culturable microbe or microbial community. 
1 A. K. Gregg ${ }^{1 *}$, M. Hatay ${ }^{2}$, A. F. Haas $^{1}$, N. L. Robinett ${ }^{1}$, K. Barott ${ }^{3}$, M. J. A. Vermeij ${ }^{4,5}$, K.

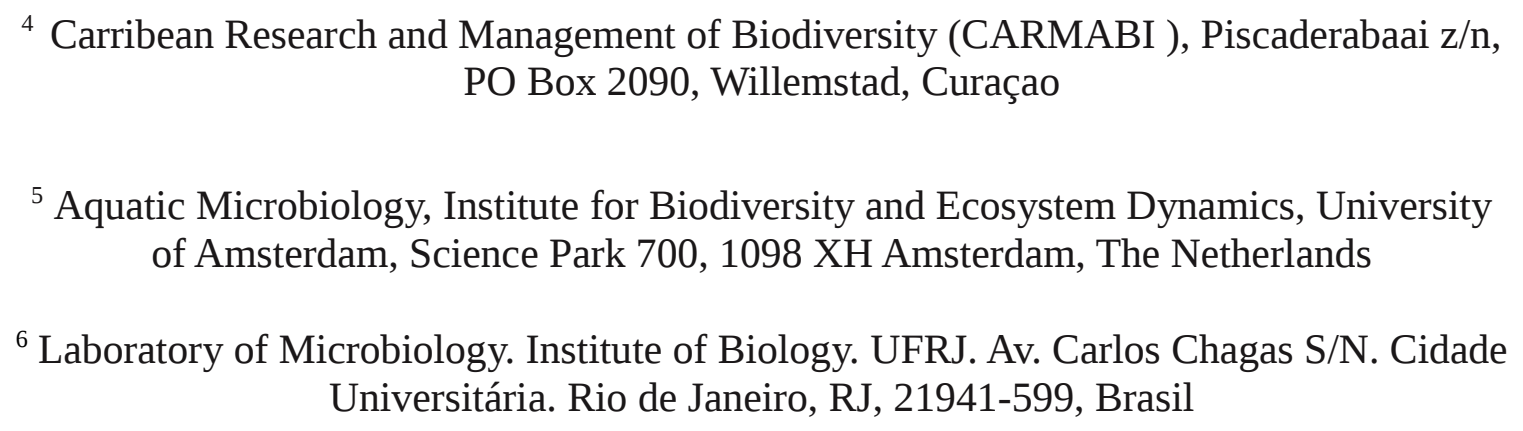

${ }^{4}$ Carribean Research and Management of Biodiversity (CARMABI ), Piscaderabaai z/n, PO Box 2090, Willemstad, Curaçao

${ }^{5}$ Aquatic Microbiology, Institute for Biodiversity and Ecosystem Dynamics, University of Amsterdam, Science Park 700, 1098 XH Amsterdam, The Netherlands

${ }^{6}$ Laboratory of Microbiology. Institute of Biology. UFRJ. Av. Carlos Chagas S/N. Cidade Universitária. Rio de Janeiro, RJ, 21941-599, Brasil

* Corresponding author: Allison K. Gregg 5500 Campanile Dr., San Diego, CA, 92182 (925) 437-1661 agregg88@gmail.com

41 

61 than others, Lennon and Pfaff 2005).

62

63 64

\section{Introduction}

Over-fishing and eutrophication are associated with increasing abundances of turf algae (McClanahan et al. 2002, Dulvy et al. 2004, Sandin et al. 2008, Vermeij et al. 2010) and coral mortality worldwide (Done 1992, Harvell et al. 1999, Harvell et al. 2007, Hughes et al. 2007). These degraded systems are also associated with increased microbial abundances (Dinsdale et al. 2008, Bruce et al. 2012) and greater microbial energy usage (McDole et al. 2012). Turf algae produce higher amounts of bioavailable dissolved organic carbon (DOC) than calcifying reef organisms such as coral and crustose coralline algae (CCA), and this DOC promotes microbial growth and respiration (Wild et al. 2010, Haas et al. 2011). Further, increasing amounts of bioavailable DOC (e.g., glucose, algal exudates) can lead to coral mortality (Kline et al. 2006), and these effects can be prevented by the addition of antibiotics, suggesting microbially mediated mechanisms are involved (line et al. 2006, Smith et al. 2006). However, algal DOC can vary significantly across algal species in terms of their monosaccharide composition (Nelson et al. 2013). This variation can differentially affect the growth of pelagic microbes, with turf algae able to support greater abundances of pelagic coral reef microbes than other types of reef-associated algae (Haas et al. 2011). This variation can also be seen in freshwater systems where terrestrial DOC runoff from trees differentially fuels microbial communities (i.e. some tree species-derived DOC supports greater bacterial production

Various studies have demonstrated that dissolved oxygen (DO) concentrations are significantly reduced at coral-algal interfaces (Barott et al. 2009, 2011b, but see Wangpraseurt et al. 2012) and on average over a diurnal cycle in the water column 
65 overlying algal beds (

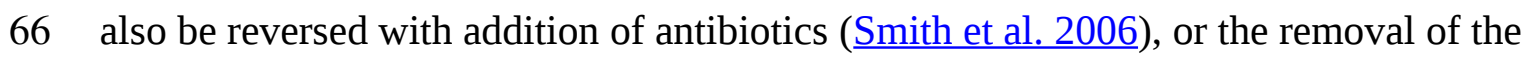

67 alga (Barott et al. 2011b). Taken together, this evidence supports the hypothesis that algal

68 induced microbially-mediated hypoxia plays a significant role in interaction processes

69 structuring the benthic reef environments. Based on these observations, the Disease,

70 DOC, Algae and Microbe (DDAM) model has been proposed in which fleshy

71 algal-derived DOC stimulates rapid microbial growth, which creates hypoxic zones and

72 results in coral stress and suffication (Kuntz et al. 2005, Kline et al. 2006, Rohwer et al.

73 2010, Dinsdale and Rohwer 2011, Barott and Rohwer 2012). It is imporant to note,

74 however, that in contrast to the non-calcifying turf and macroalgae, hypoxia has not been

75 observed on borders between CCA and corals and these interactions do not appear to be

76 harmful to most corals (Barott et al. 2009, Vermeij et al. 2010, Barott et al. 2011b).

77 Furthermore, coral recruits preferentially settle on some types of CCA (e.g., Titanoderma

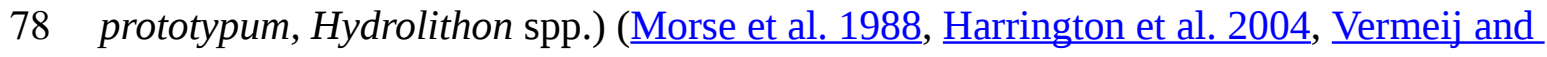

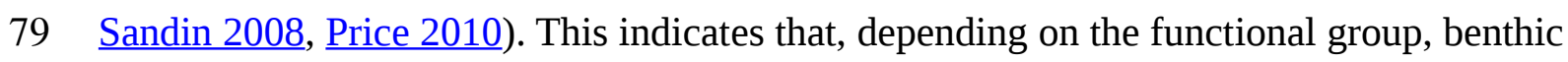

80 algae can either benefit or hinder adjacent corals.

81 Planar optodes are a useful tool to investigate these spatially distinct dynamics in a

82 coral reef system. Using a luminescent indicator they are able to visualize the concentrations

83 of a broad range of compounds (Glud et al. 1996) including oxygen, $\mathrm{pH}$, carbon dioxide, and

84 glucose (for review, see (Borisov and Wolfbeis 2008). Another expanding area within optical

85 sensors is the use of whole cell bacterial biosensors for the measurement of biological

86 oxygen demand (BOD), which have been used to extrapolate water quality in aquatic

87 environments (Preininger et al. 1994, Kwok et al. 2005, Jiang et al. 2006, Lin et al. 2006). 
88 These sensors take advantage of microbial cells immobilized in a matrix and coupled to an

89 oxygen transducer. Oxygen planar and micro-optodes have previously only been applied to

90 the study of coral reefs under controlled lab conditions (Wild et al. 2004, Kuhl and Polerecky

91 2008, Haas et al. submitted-a). Larsen et al. (2011) showed for the first time that spatial

92 oxygen dyanamics can be accurately monitered using commercially available compact digital

93 cameras. Expanding upon this method described in Larsen et al. (2011), we have developed a

94 fully submersible, time-lapsed oxygen optode system (SOOpR). This system is capable of

95 measuring oxygen concentrations in two dimensions, as well as BOD of reef associated

96 microbes.

97 Given the differences in DOC production rates (Haas et al. 2011), secondary

98 metabolites (Morrow et al. 2011), and microbes (Barott et al. 2011a, Barott et al. 2011b)

99 associated with different functional groups of benthic reef algae, we hypothesized that

100 coral-associated microbes will exhibit differential responses to exudates from the various

101 algal guilds. To investigate this hypothesis, we utilized BOD optodes embedded with a

102 microbial community cultured from the corals Montastraea annularis and Mussismilia

103 hispida to measure respiration when exposed to exudates generated by turf algae and CCA.

104

105 Materials and Methods

106 Lighting and camera system: Images of BOD optode plates were taken every 5

107 min over a $7 \mathrm{hr}$ period using the submersible oxygen optode recorder (SOOpR) system.

108 SOOpR consists of an automated camera and excitation source that is able to be fully

109 submerged underwater. A Powershot G11 camera (Canon, USA) equipped with the

110 Canon Hack Development Kit (CHDK, Firmware version 1.00L). CHDK is an open 
111 source program that adds new features to the camera's standard options, such as

112 timelapse photography, which was used in this study. The CHDK hack was outfitted with

113 the Ultra Intervalometer script (originally written by Keoeeit (2010); Supplementary data,

114 Fig. S1) to allow for timelapse photography. Camera settings were set to a shutter speed

115 of 1/20”, and F-stop of 4.5 and ISO at 100.

116 The camera was encased in a WP-DC34 underwater housing (Canon, USA).

117 Excitation light was supplied from custom built underwater strobes optically triggered by

118 the flash of the camera. Two YS-300 stobe housings were gutted of original contents to

119 allow space for custom lighting (Sea\&Sea SUNPAK Co., USA). Strobes were equipped

120 with three $447.5 \mathrm{~nm}$ Royal Blue tri-star $2730 \mathrm{~mW}$ light emitting diodes (LED)

121 (Phillips-Luxeon, Canada) to excite the indicator. LED were covered by a blue dichroic

122 filter (UQG Optics, United Kingdom) to block the tail end of the light spectrum emitted.

123 The LED were controlled with an arduino-based microcontroller, Camera Axe 5, which

124 allows for triggering of a camera or flash using various signals (Camera Axe, USA). The

125 Camera Axe 5 was used to trigger the LED via the optical signal of the camera's flash.

126 The flash was coupled to a photodetector (OSRAM Opto Semiconducters, USA) inside

127 of the strobe housing using a $2000 \mu$ m fiber optic cable (Edmund Optics, USA), which

128 signaled the Camera Axe to turn on the bank of LED for excitation (Figure 1b). Camera

129 Axe settings were a bulb time of $2 \mathrm{~s}$ and an optical trigger threshold of 25. Underwater

130 housing was equipped with a Schott $530 \mathrm{~nm}$ longpass filter (UQG Optics, United

131 Kingdom) to block excitation source from contamintaing luminescent signal. The camera

132 system was positioned $20 \mathrm{~cm}$ from subject and strobes were oriented approximately $20^{\circ}$

133 from the horizontal plane of camera (Fig.1a). 
135 constuct a 96-well BOD optode plate. Spray mount adhesive (3M, USA) was applied

136 onto one side of the carrier and a planar oxygen optode was fixed to it. The optode was

137 oriented with the oxygen reactive side of the optode facing the interior of the wells (Fig.

138 2b). Care was taken to ensure that the optode exposed to the inside of the well was not

139 disturbed by adhesive. The oxygen optode sheets were prepared according to Larsen et al

140 (2011). The wells constituting the perimeter of the plate were not used.

141 Calibration of optodes-A calibration was performed by recording images of each

142 optode in known oxygen concentrations ranging from 100\% air saturation to anoxia.

143 Starting concentration of the calibration was $\sim 250 \mu \mathrm{M}$ DO, which was then saturated

144 with nitrogen gas (AirGas, USA) to decrease the concentration of oxygen in the

145 calibration chamber. Oxygen concentrations were measured using an LBOD101

146 Luminescent DO probe (Hach Lange, Germany), and images were taken at

147 approximately $30 \mu \mathrm{M}$ step decreases until water reached anoxia. The ratios of these

148 images were then used to determine $\mathrm{K}_{\mathrm{sv}}$ and $\alpha$ for each plate.

149 Experiment 1- Algal exudate studies

$150 \quad$ Culturing microbes: Montastraea annularis and Mussismilia hispida mucus

151 samples were collected at $\sim 5 \mathrm{~m}$ depth using a syringe on the south coast of Curaçao

152 (Water factory, $12^{\circ} 06^{\prime} 34.18^{\prime \prime} \mathrm{N}, 68^{\circ} 57^{\prime} 16.22^{\prime}$ W) and the east coast of Brazil (Arraial do

153 Cabo, 2259'6.96" S, 4159'30.57" W), respectively. One-hundred microliters of the

154 sample was spread onto a 1:1 marine media agar plate (BD Difco, USA) and incubated

155 for $24 \mathrm{hr}$ at ambient room temperature ( $31 \pm 1^{\circ} \mathrm{C}$ in Curaçao, $21 \pm 0.5^{\circ} \mathrm{C}$ in Brazil). 
156 The resulting mixed community was rinsed off the plate with $3 \mathrm{ml}$ of $0.22 \mu \mathrm{m}$ filtered

157 seawater and this stock was diluted to an optical density of $0.5 \pm 0.015(\lambda=600 \mathrm{~nm})$.

158 Sixty microliters of sterile $0.5 \%$ top agar (BD Difco, USA) was added to every

159 other well as a control. Then $60 \mu \mathrm{l}$ of the top agar with the mixed microbial community

160 from M. annularis or M. hispida were added to the remaining wells. The top agar was

161 kept at $42^{\circ} \mathrm{C}$ prior to the addition of the mixed microbial community (Spencer 1952). For

162 the microbial wells, the $\mathrm{OD}_{600}=0.5$ community was added to the warmed top agar at 1:10.

163 The resulting plates were allowed to solidify at room temperature and used within $1 \mathrm{hr}$ of

164 production.

165 Production of exudates: For experiments involving M. annularis, rubble covered

166 with turf or CCA was collected at a depth of < $5 \mathrm{~m}\left(12^{\circ} 07^{\prime} 18.71^{\prime \prime} \mathrm{N}, 68^{\circ} 58^{\prime} 09.57^{\prime \prime} \mathrm{W}\right)$

167 and transported to the lab within one hour. The algae-encrusted rubble was spread over

168 the bottom of a $10 \mathrm{l}$ buckets $\left(380 \mathrm{~cm}^{2}\right)$ and filled with $4 \mathrm{l}$ of seawater. Exudates were

169 normalized by surface area of the algal substrate. The buckets were kept in diffused

170 sunlight and bubbled with air for a full daylight cycle. The exudates were filtered through

171 a $10 \mu \mathrm{m}$ nylon mesh (Filter Specialists Inc., USA) to remove large particulates. The

172 temperature of the exudates was $27 \pm 1^{\circ} \mathrm{C}$. For experiments using $M$. hispida, rubble

173 covered with turf algae or CCA was collected at a depth between 5-10 m and was kept in

174 a cooler to be transported back to the lab within $4 \mathrm{hr}$. The algae encrusted rubble was

175 spread over the bottom of $2 \mathrm{l}$ beakers (Pyrex) and filled with $1800 \mathrm{ml}$ of Coral Pro Salt

176 artificial seawater (Red Sea, USA). The beakers were kept under artificial daylight

177 provided by 2 x 54W Marine-glo T5 HO (Rolf C. Hagen Inc., Canada) + 1 x 250W 14K

178 HQI (Hamilton Bulb, USA) and bubbled with air for a full daylight cycle. The exudates 
179 were filtered through $10 \mu \mathrm{m}$ nylon mesh to remove larger particulates. The temperature of

180 the exudates was maintained at $22 \pm 1^{\circ} \mathrm{C}$. Special care was taken to control for surface

181 cover (area), so the difference that are due to available substrate would likely be seen in

182 situ as well.

183 Incubations were performed with exudates from turf algae, CCA, or seawater. For

184 each exudate treatment, a BOD plate was submerged within one liter of exudate in an

185 acrylic aquarium. Any trapped air bubbles were removed by tapping the wells and the

186 plates were then kept in the dark for $7 \mathrm{hr}$, and imaged by the SOOpR sytem every $5 \mathrm{~min}$.

187 Optodes used for these experiments were calibrated at $27 \pm 0.5^{\circ} \mathrm{C}$ and $22 \pm 0.5^{\circ}$ for $M$.

188 annularis and M. hispida, respectively.

189 Experiment 2- Single strain studies: One-hundred microliters of the M. annularis

190 mucus sample was plated on a $1.5 \%$ seawater agar plate (BD Difco, USA) and incubated

191 for $48 \mathrm{hr}$ at ambient room temperature $\left(31 \pm 1^{\circ} \mathrm{C}\right)$. Four colonies with different

192 phenotypes were isolated and streaked onto 1:1 marine media agar plate (BD Difco,

193 USA) and incubated for $24 \mathrm{hr}$ at room temperature. The plates of each isolate were rinsed

194 with $3 \mathrm{ml}$ of $0.02 \mu \mathrm{m}$ filtered seawater to remove the bacteria, and this stock was diluted

195 to an optical density of $0.5 \pm 0.015(\lambda=600 \mathrm{~nm})$. Sixty microliters of sterile $0.5 \%$ top

196 agar (BD Difco, USA) was added as a negative control in the columns between each

197 treatment. The cultured stocks containing the single strain isolates were added to every

198 other column and incubations were performed in turf algal exudate as described above.

199 Experiment 3-Different organism-associated bacteria assemblage study: Water

200 samples from the surface of turf algae, CCA, and coral were obtained from specimen

201 raised in aquaria at Scripps Institution of Oceanography (San Diego, CA, USA) for $\sim$ six 
202 months. One-hundred microliters of each water sample was plated on 1:1 marine media 203 agar plates (BD Difco, USA) and incubated at $30^{\circ} \mathrm{C}$ for $24 \mathrm{hr}$. The plate was then rinsed 204 with $3 \mathrm{ml}$ of $0.02 \mu \mathrm{m}$ filtered seawater and the stock was diluted to an optical density of $2050.5 \pm 0.015(\lambda=600 \mathrm{~nm})$. Sixty microliters of sterile $0.5 \%$ top agar (BD Difco, USA) was 206 added as a negative control in the rows between each treatment. The remaining rows were 207 filled with the cultured stocks of bacterial communities associated with the different 208 organisms (turf algae, coral and CCA).

209 Turf algal exudates were prepared by covering the bottom of a glass aquarium $210\left(273 \mathrm{~cm}^{2}\right)$ with turf encrusted rubble (Scripps Institution of Oceanography, San Diego,

211 USA) and filled with 3 liters of water. The aquaria was bubbled with air and left to exude 212 for a full daylight cycle under artificial light, which was provided by 2 x 54 W 6000K 213 Aquablue + , 1 x $54 \mathrm{~W}$ 6000K Midday, and 1 x $54 \mathrm{~W}$ Actinic $^{+}$aquarium lights 214 (Geismann, Germany), mounted $80 \mathrm{~cm}$ above the experimental area, resulting in 215 photosynthetic active radiation of $120 \mu \mathrm{mol}$ quanta $\mathrm{m}^{-2} \mathrm{~s}^{-1}$ as measured by a LI-COR 216 LI-193 Spherical Quantum Sensor. The turf exudate was sterilized using a $0.22 \mu \mathrm{m}$ 217 Sterivex $^{\mathrm{TM}}$ filter (Millepore, USA). The temperature of the exudates was $25 \pm 1^{\circ} \mathrm{C}$.

218 Optodes used for these experiments were calibrated at $25 \pm 0.5^{\circ} \mathrm{C}$

219 Sequencing of M. annularis isolates: Genomic DNA was extracted from the four 220 bacterial isolates cultured from M. annularis mucus using the NucleoSpin® Genomic 221 DNA Tissue Kit (Macherey-Nagel, Germany). The 16S rRNA genes were amplified by 222 PCR. The bacterial primers 27F (5'-AGAGTTTGATCMTGGCTCAG) and 1492R 223 (5'-TACGGYTACCTTGTTACGACTT) were used and the thermocycler conditions were 224 as follows: initial denaturation step ( 5 min at $94^{\circ} \mathrm{C}$ ), 30 cycles of denaturation ( $1 \mathrm{~min}$ at 9 
$22594^{\circ} \mathrm{C}$ ), annealing ( $30 \mathrm{sec}$ at $65^{\circ} \mathrm{C},-0.5^{\circ} \mathrm{C}$ per cycle), and elongation $\left(1 \mathrm{~min}\right.$ at $72^{\circ} \mathrm{C}$ ),

226 with a final elongation for $10 \mathrm{~min}$ at $72^{\circ} \mathrm{C}$, then cooled to $4^{\circ} \mathrm{C}$. $16 \mathrm{~S}$ amplicons were

227 verified by viualizing the correct band size using gel electrophoresis (1\% agarose gel)

228 stained with ethidium bromide. PCR products were then purified using the QIAquick ${ }^{\circledR}$

229 PCR Purification Kit (Qiagen, The Netherlands). Amplicons were then sequenced in both

230 directions with the forward and reverse primers using Sanger sequencing (Eton

231 Bioscience Inc., CA, USA). Isolates were identified to the nearest known relative using

232 The Ribosomal Database Project (http://rdp.cme.msu.edu).

233 Image analysis: All images were recorded in RAW mode and converted to three

234 16-bit TIFF images (red, averaged green, and blue) using RawHide image conversion

235 software (v0.88.001, My-Spot Software, USA). The resulting images were imported into

236 Image (v1.44o, NIH Software, USA) to determine red and green pixel intensities for

237 each well. A 300-pixel box was made on the image that filled the area of the well. The

238 avergae pixel intensity within the region of interest was determined for each well. This

239 process was done for both red and green images. These pixel intensities were used to

240 calculate R (Eq. 1).

$$
R=\frac{\text { (intensity of red }- \text { intensity of green) }}{\text { intensity of green }}
$$

243 Oxygen concentrations were calculated using the modified Stern-Volmer equation (Eq.

244 2), where $R_{0}$ is the ratio at anoxia, $C$ is the concentration of dissolved oxygen, $K_{s v}$ is the

245 Stern-Volmer quenching constant, and $\alpha$ is the unquenchable fraction of the optode

246 (Klimant et al. 1995). 


$$
\frac{R}{R 0}=\left[\alpha+(1-\alpha)\left(\frac{1}{1+K s v \times C}\right)\right]
$$

and R (Prism version 5, R version 2.13.2). Unless otherwise stated, all statistics were performed on the changes in dissolved oxygen from $T_{\text {initial }}$ to $T_{\text {final. }}$ A Kruskal-Wallis test was used to determine if there were significant differences in dissolved oxygen concentration amongst the treatments $(\alpha=0.05)$. Two-tailed Mann-Whitney tests were performed to determine if the starting concentration of dissolved oxygen in each treatment was statistically different between the control and bacterial wells, as well as between treatments. All results written as mean $\pm \mathrm{SE}$.

\section{Results and Discussion}

Validation of camera system: A modular camera and excitation system,

260 submersible oxygen optode recording (SOOpR) system, capable of operating

261 autonomously and fully submerged was developed here. Optode excitation analysis in the

262 SOOpR system generated two visible peaks corresponding to Macrolex Yellow (550 nm)

263 and platinum (II) octaethylporphyrin (PtOEP) (650 nm), as expected (Supplementary

264 data, Fig. S2). These peaks were consistent with those seen in the study described by

265 Larsen et al. (2011). Additionally, calibration of the oxygen optode sheet was performed

266 to validate whether measured values of DO compared to values calculated from the

267 Stern-Volmer equation. From the recorded image, oxygen concentration of seawater was

268 determined to be $191.6 \mu \mathrm{M}$. This was cross-referenced by measuring the oxygen 
269 concentration of the same seawater using the LBOD Probe; measured concentration was

$270188.8 \mu \mathrm{M}$. The SOOpR system is capable of being fully submerged to depths greater than

$27110 \mathrm{~m}$ and able to accurately measure oxygen concentrations. This provides a novel

272 method to estimate bacterial growth rates and oxygen dynamics on the reef and without

273 the use of radiation necessary for other bacterial growth assays (e.g. thymidine and

274 leucine incorporation) (Fuhrman and Azam 1982, Kirchman et al. 1985).

275 Bacterial isolates respond differently to turf algal exudate: Individual bacterial

276 isolates cultured from M. annularis mucus were tested to investigate whether bacterial

277 strains differentially respond to turf algal-derived exudates. For this purpose exudates

278 derived from turf algae were used as they proved in previous studies to foster noticeable

279 elevations in microbial oxygen demand (

280 that select coral-associated microbial isolates had significantly different oxygen

281 consumption rates when exposed to the introduced turf exudates. Isolate one consumed

282 significantly more oxygen in the presence of turf exudate than any other isolate (Fig. 2,

$28384.49 \pm 7.44$, Mann-Whitney test $\mathrm{p}<0.01$ ). Sequencing of the $16 \mathrm{~S}$ ribosomal subunit

284 identified isolates one, two, and four as Psuedoalteromonas spp. and isolate three in the

285 family Bacillaceae. Nelson et al. (2013) found that bacteria from the family

286 Pseudoalteromonadaceae were significantly enriched in fleshy algal exudates compared

287 to calcifying organism exudates (i.e., Halimeda sp. and coral). This differential response

288 shows that introduction of organic matter sources can differentially alter the activity of

289 microbes naturally residing in the coral mucus.

290 Bacterial communities cultured from coral, turf algae, and CCA respond similarly

291 to turf algal exudate: To assess bacterial community responses to algal DOM, bacteria 
292 associated with different functional groups (turf/CCA/coral) were exposed to turf algal

293 exudates and the oxygen drawdown was determined. Bacterial communities drew down

294 similar amounts of oxygen when exposed to turf exudate, regardless of their original host

295 (Fig. 3, mean $=156.52 \pm 8.02$ ). Although individual microbial isolates respond

296 differentially to turf exudate, there appears to be sufficient functional redundancy in all of

297 the communities to respond in a similar manner. However, possible lab culturing bias

298 could account for this observation. These results suggest that it is the addition of turf

299 algal exudates that accounts for the large drawdown of oxygen, as opposed to the specific 300 community of microbes introduced.

$301 \quad$ Turf algae elicit the greatest oxygen drawdown by coral-associated bacteria: One

302 mechanism likely contributing to decrease in coral health is hypoxia at borders where

303 corals are in close proximity with turf or macroalgae (Smith et al. 2006, Barott et al.

304 2009, Barott et al. 2011b). Our studies were carried out to investigate how organic matter

305 derived from benthic algae can affect the oxygen consumption rates of microbial

306 communities associated with both corals and algae. To do this, bacterial community

307 cultures from M. annularis and M. hispida were exposed to exudates from turf algae and

308 CCA to assess whether respiration was differentially affected by algal DOM source. Both

309 M. annularis and M. hispida BOD plates showed an overall decrease in dissolved oxygen

310 concentrations in all wells over the period of 7 hours (Fig. 4).

311 For the M. annularis BOD plates, the DO drawdown of the bacterial wells was

312 significantly higher in the turf treatment $(272.45 \pm 11.67 \mu \mathrm{M})$ compared to the CCA

313 treatment $(105.27 \pm 6.79 \mu \mathrm{M})$ and the seawater control (61.44 $\pm 6.52 \mu \mathrm{M}$; Fig. 5a,

314 Mann-Whitney test $\mathrm{p}<0.0001)$. The control wells in the turf and CCA exudate treatment 
315 also showed oxygen drawdown over the $7 \mathrm{hr}$ period, although not as great as the wells

316 inoculated with bacteria. As with the microbial community associated with M. annularis,

317 both exudate treatments caused the microbial communities cultured from M. hispida to

318 draw down significantly more oxygen than the seawater control (Fig. 5b, Mann-Whitney

319 test $\mathrm{p}=0.0003$ and 0.004 for turf and CCA, respectively). In the presence of turf algal

320 exudate, $M$. hispida- associated microbial communities also drew down more oxygen

321 compared to CCA exudate; however, this difference was not statistically significant

322 (Mann-Whitney test, $\mathrm{p}=0.07$ ). These differences between M. annularis and M. hispida

323 may be explained by differences in the composition of the microbial communities

324 associated with each of these species (de Castro et al. 2010, Barott et al. 2011a). Similar

325 to the M. annularis studies, the controls in the M. hispida experiment exposed to both turf

326 and CCA exudate drew down greater than $90 \mu \mathrm{M}$ of oxygen. There was no statistically

327 significant difference in the DO consumption of the bacterial and control wells within the

328 turf algae (Mann-Whitney test, $\mathrm{p}=0.167$ ) or CCA (Mann-Whitney test, $\mathrm{p}=0.489$ )

329 treatment for M. hispida-associated communities. This suggests that the ambient

330 microbes present during the algal exudate incubations (i.e. water column- or

331 algal-associated) were consuming a large amount of oxygen in the presence of this

332 algal-generated organic matter, leading to drawdown of oxygen detected within the

333 control wells (Fig. 5). Together, these data show that bacterial communities are able to

334 consume turf-algal exudates more readily than exudates derived from the calcifying

335 CCA. It has been previously shown that turf algae generate more DOC than CCA, which

336 leads to increased microbial oxygen consumption (Haas et al. 2011). In addition,

337 allelochemicals released by cyanobacteria can stimulate bacterial growth (Morrow et al. 
338 2011). As cyanobacteria are often present in turf algal assemblages (Fong and Paul 2011),

339 it is possible that these secondary metabolites may have aided in the enhanced microbial

340 growth observed in this study. Further studies to characterize the chemical composition

341 of algal exudates should be conducted.

342 It has been documented that reef bacteria readily consume algal-derived organic

343 matter (Cole et al. 1982, Wild et al. 2010, Haas et al. 2011) leading to increased

344 abundances; however, introduction of a novel organic matter source may also alter the

345 community of microbes present (Carlson et al. 2004). Naturally occurring

346 coral-associated microbial community structure can shift towards pathogenic bacteria

347 when DOC is introduced (Thurber et al. 2009) and when corals are in contact with fleshy

348 algae (Barott et al. 2011b). Furthermore, pelagic microbial communities incubated with

349 fleshy algal exudates became enriched with copiotrophic bacteria including potential

350 pathogens (Nelson et al. 2013). Taken together with these findings, the results of this

351 study indicate that not only can algal derived dissolved organic matter significantly

352 increase culturable microbial community metabolism, but can also select for individual

353 strains of culturable bacteria, potentially disturbing the homeostasis of the coral holobiont

354 (Rohwer et al. 2001, 2002).

355 Caveats: In this study we utilize nutrient rich media, which selects for

356 fast-growing heterotrophic microbes. Although this could confound our results by

357 overestimating the heterotrophic nature of the in situ community, Haas et al. (2011)

358 showed that turf algal exudate elicited the highest microbial growth response in

359 culture-independent pelagic microbes. Therefore it is likely this trend would also be seen

360 using uncultivable methods. One drawback of our experimental design was that the 
361 algal exudates in the field studies were not $0.22 \mu \mathrm{m}$ filtered. This could possibly

362 confound our results because the microbes that grew during the exuding process could

363 potentially be very different than those naturally residing on the algae due to the effects

364 of growing in a confined space (Zobell and Anderson 1936, Ferguson et al. 1984, Lee and

365 Fuhrman 1991).

366 Finally, the exudate concentrations used here likely exceed in situ values, which

367 could call into question the biological relevance of the proposed mechanism. However,

368 the accompanying study by Haas et al (submitted-b) indicates that responses of

369 reef-associated microbial communities are significantly more dependent on the source of

370 exudates than concentration.

371

372 Conclusion

373 This study supports the hypothesis that hypoxia in close proximity to turf algae is

374 driven in part by increased microbial oxygen demand. Despite variation in oxygen

375 demand of individual bacterial strains, oxygen draw down at the community level

376 showed no significant differences among different community types. Changes in the

377 source of organic matter, on the other hand, affected oxygen consumption rates of

378 cultured bacterial communities significantly. This suggests that hypoxia, commonly

379 found at the interface of coral-algal interactions, is a result of the complex interactions of

380 coral-associated microbial communities and the properties of the organic matter

381 available. The increased input of bioavailable DOM accompanying phase shifts from a

382 calcifier (e.g. CCA and coral) to a non- calcifier dominated system (e.g. turf and fleshy

383 macroalgae), can thus change microbial metabolism in a way that oxygen demand 
384 outweighs production, possibly leading to a shift towards a net heterotrophic microbial 385 reef community (See companion study (ㅂaas et al. submitted-b). Initially, these effects

386 are likely taking place on a very small spatial scale; however, due to the DDAM positive

387 feedback loop, turf algae is able to slowly crawl further in on the coral eventually

388 overgrowing it, potentially leading to coral-algal phase shifts. Similar results of turf

389 exudate-induced increases of microbial respiration, obtained from two different ocean

390 systems, suggest that this microbially-mediated hypoxic stress could have important

391 implications in the structure and health of the worlds coral reef systems.

392

\section{Acknowledgements}

394 We thank CARMABI in Curaçao and the Thompson lab in Brazil for their facilities and 395 Birch Aquarium at Scripps Institution of Oceanography for supplying us with algal and 396 coral specimen. We thank Franklin Holub for his generous technical support with

397 RawHide and Alex Hewitt for his expertise with CHDK. We thank Linda Kelly and

398 Steven Quistad for their helpful comments throughout the scientific and writing process.

399 We also thank Reviewers Kathleen Morrow and Mike Sweet for their extremely helpful 400 comments on this manuscript.

401 


\section{References}

404

405

406

407

408

409

410

411

412

413

414

415

416

417

418

419

420

421

422

423

424

425

426

427

428

429

430

431

432

433

434

435

436

437

438

439

440

441

442

443

444

445

Barott, K., J. Smith, E. Dinsdale, M. Hatay, S. Sandin, and F. Rohwer. 2009. Hyperspectral and physiological analyses of coral-algal interactions. PLoS One 4.

Barott, K. L., B. Rodriguez-Brito, J. Janouskovec, K. L. Marhaver, J. E. Smith, P. Keeling, and F. L. Rohwer. 2011a. Microbial diversity associated with four functional groups of benthic reef algae and the reef-building coral Montastraea annularis. Environmental Microbiology 13:1192-1204.

Barott, K. L., B. Rodriguez-Mueller, M. Youle, K. L. Marhaver, M. J. Vermeij, J. E. Smith, and F. L. Rohwer. 2011b. Microbial to reef scale interactions between the reef-building coral Montastraea annularis and benthic algae. Proceedings. Biological sciences / The Royal Society.

Barott, K. L. and F. L. Rohwer. 2012. Unseen players shape benthic competition on coral reefs. Trends in Microbiology 20:621-628.

Borisov, S. M. and O. S. Wolfbeis. 2008. Optical biosensors. Chemical Reviews 108:423-461.

Bruce, T., P. M. Meirelles, G. Garcia, R. Paranhos, C. E. Rezende, R. L. de Moura, R. F. Filho, E. O. C. Coni, A. T. Vasconcelos, G. Amado, M. Hatay, R. Schmieder, R. Edwards, E. Dinsdale, and F. L. Thompson. 2012. Abrolhos Bank Reef Health Evaluated by Means of Water Quality, Microbial Diversity, Benthic Cover, and Fish Biomass Data. PLoS One 7.

Carlson, C. A., S. J. Giovannoni, D. A. Hansell, S. J. Goldberg, R. Parsons, and K. Vergin. 2004. Interactions among dissolved organic carbon, microbial processes, and community structure in the mesopelagic zone of the northwestern Sargasso Sea. Limnology and Oceanography 49:1073-1083.

Cole, J. J., G. E. Likens, and D. L. Strayer. 1982. Photosynthetically produced dissolved organic carbon: an important carbon source for planktonic bacteria. Limnology and Oceanography 27:1080-1090.

de Castro, A. P., S. D. Araujo, A. M. M. Reis, R. L. Moura, R. B. Francini, G. Pappas, T. B. Rodrigues, F. L. Thompson, and R. H. Kruger. 2010. Bacterial community associated with healthy and diseased reef coral Mussismilia hispida from eastern Brazil. Microbial Ecology 59:658-667.

Dinsdale, E. and F. Rohwer. 2011. Fish or germs? Microbial dynamics sssociated with changing trophic structures on coral reefs. Pages pp 231-240 in Z. Dubinsky and N. Stambler, editors. Coral Reefs: An ecosystem in transition. Springer Netherlands.

Dinsdale, E. A., O. Pantos, S. Smriga, R. A. Edwards, F. Angly, L. Wegley, M. Hatay, D. Hall, E. Brown, M. Haynes, L. Krause, E. Sala, S. A. Sandin, R. V. Thurber, B. L. Willis, F. Azam, N. Knowlton, and F. Rohwer. 2008. Microbial ecology of four coral atolls in the northern Line Islands. PLoS One 3.

Done, T. J. 1992. Phase-shifts in coral reef communities and their ecological significance. Hydrobiologia 247:121-132.

Dulvy, N. K., R. P. Freckleton, and N. V. C. Polunin. 2004. Coral reef cascades and the indirect effects of predator removal by exploitation. Ecology Letters 7:410-416. 
446

447

448

449

450

451

452

453

454

455

456

457

458

459

460

461

462

463

464

465

466

467

468

469

470

471

472

473

474

475

476

477

478

479

480

481

482

483

484

485

486

487

488

489

490

491

Ferguson, R. L., E. N. Buckley, and A. V. Palumbo. 1984. Response of marine bacterioplankton to differential filtration and confinement. Applied and Environmental Microbiology 47:49-55.

Fong, P. and V. J. Paul. 2011. Coral reef algae. Pages 241-272 in Z. Dubinsky and N. Stambler, editors. Coral Reefs: An Ecosystem in Transition. Springer Netherlands.

Fuhrman, J. A. and F. Azam. 1982. Thymidine incorporation as a measure of heterotrophic bacterioplankton production in marine surface waters: evaluation and field results. Marine Biology 66:109-120.

Glud, R. N., N. B. Ramsing, J. K. Gundersen, and I. Klimant. 1996. Planar optrodes: A new tool for fine scale measurements of two-dimensional O-2 distribution in benthic communities. Marine Ecology-Progress Series 140:217-226.

Haas, A. F., A. K. Gregg, J. E. Smith, M. L. Abieri, M. Hatay, and F. Rohwer. submitted-a. Visualization of oxygen distribution patterns generated by coral and algae.

Haas, A. F., C. Jantzen, M. S. Naumann, R. Iglesias-Prieto, and C. Wild. 2010. Organic matter release by the dominant primary producers in a Caribbean reef lagoon: implication for in situ $\mathrm{O}(2)$ availability. Marine Ecology-Progress Series 409:27-39.

Haas, A. F., C. E. Nelson, F. Rohwer, L. Wegley Kelly, C. A. Carlson, J. J. Leichter, and J. E. Smith. submitted-b. Influence of coral and alga exudates on microbially mediated reef metabolism

Haas, A. F., C. E. Nelson, L. Wegley Kelly, C. A. Carlson, F. Rohwer, J. J. Leichter, A. Wyatt, and J. E. Smith. 2011. Effects of coral reef benthic primary producers on dissolved organic carbon and microbial activity. PLoS One 6:e27973.

Harrington, L., K. Fabricius, G. De'Ath, and A. Negri. 2004. Recognition and selection of settlement substrata determine post-settlement survival in corals. Ecology 85:3428-3437.

Harvell, C. D., E. Jordán-Dahlgren, S. Merkel, E. Rosenberg, L. Raymundo, G. Smith, E. Weil, and B. Willis. 2007. Coral disease, environmental drivers, and the balance between coral and microbial associates. Oceanography 20:172-195.

Harvell, C. D., K. Kim, J. M. Burkholder, R. R. Colwell, P. R. Epstein, D. J. Grimes, E. E. Hofmann, E. K. Lipp, A. D. Osterhaus, R. M. Overstreet, J. W. Porter, G. W. Smith, and G. R. Vasta. 1999. Emerging marine diseases--climate links and anthropogenic factors. Science 285:1505-1510.

Hughes, T. P., M. J. Rodrigues, D. R. Bellwood, D. Ceccarelli, O. Hoegh-Guldberg, L. McCook, N. Moltschaniwskyj, M. S. Pratchett, R. S. Steneck, and B. Willis. 2007. Phase shifts, herbivory, and the resilience of coral reefs to climate change. Current Biology 17:360-365.

Jiang, Y., L. L. Xiao, L. Zhao, X. Chen, X. Wang, and K. Y. Wong. 2006. Optical biosensor for the determination of BOD in seawater. Talanta 70:97-103.

Keoeeit. 2010. Ultra Intervalometer. CHDK.

Kirchman, D., E. Knees, and R. Hodson. 1985. Leucine incorporation and its potential as a measure of protein synthesis by bacteria in natural aquatic systems. Applied and Environmental Microbiology 49:599-607.

Klimant, I., V. Meyer, and M. Kuhl. 1995. Fiberoptic oxygen microsensors, a new tool in aquatic biology. Limnology and Oceanography 40:1159-1165. 
492

493

494

495

496

497

498

499

500

501

502

503

504

505

506

507

508

509

510

511

512

513

514

515

516

517

518

519

520

521

522

523

524

525

526

527

528

529

530

531

532

533

534

535

536

537

Kline, D. I., N. M. Kuntz, M. Breitbart, N. Knowlton, and F. Rohwer. 2006. Role of elevated organic carbon levels and microbial activity in coral mortality. Marine Ecology-Progress Series 314:119-125.

Kuhl, M. and L. Polerecky. 2008. Functional and structural imaging of phototrophic microbial communities and symbioses. Aquatic Microbial Ecology 53:99-118.

Kuntz, N. M., D. I. Kline, S. A. Sandin, and F. Rohwer. 2005. Pathologies and mortality rates caused by organic carbon and nutrient stressors in three Caribbean coral species. Marine Ecology-Progress Series 294:173-180.

Kwok, N. Y., S. J. Dong, W. H. Lo, and K. Y. Wong. 2005. An optical biosensor for multi-sample determination of biochemical oxygen demand (BOD). Sensors and Actuators B-Chemical 110:289-298.

Larsen, M., S. M. Borisov, B. Grunwald, I. Klimant, and R. N. Glud. 2011. A simple and inexpensive high resolution color ratiometric planar optode imaging approach: application to oxygen and pH sensing. Limnol. Oceanogr. Methods 9:348-360.

Lee, S. H. and J. A. Fuhrman. 1991. Species composition shift of confined bacterioplankton studied at the level of community DNA. Marine Ecology Progress Series 79:195-201.

Lin, L., L. L. Xiao, S. Huang, L. Zhao, J. S. Cui, X. H. Wang, and X. Chen. 2006. Novel BOD optical fiber biosensor based on co-immobilized microorganisms in ormosils matrix. Biosensors \& Bioelectronics 21:1703-1709.

McClanahan, T. R., B. A. Cokos, and E. Sala. 2002. Algal growth and species composition under experimental control of herbivory, phosphorus and coral abundance in Glovers Reef, Belize. Marine Pollution Bulletin 44:441-451.

McDole, T., J. Nulton, K. L. Barott, B. Felts, C. Hand, M. Hatay, H. Lee, M. O. Nadon, B. Nosrat, P. Salamon, B. Bailey, S. A. Sandin, B. Vargas-Angel, M. Youle, B. J. Zgliczynski, R. E. Brainard, and F. Rohwer. 2012. Assessing coral reefs on a Pacific-wide scale using the microbialization score. PLoS One 7.

Morrow, K., V. Paul, M. Liles, and N. Chadwick. 2011. Allelochemicals produced by Caribbean macroalgae and cyanobacteria have species-specific effects on reef coral microorganisms. Coral Reefs 30:309-320.

Morse, D. E., N. Hooker, A. N. C. Morse, and R. A. Jensen. 1988. Control of larval metamorphosis and recruitment in sympatric Agariciid corals. Journal of Experimental Marine Biology and Ecology 116:193-217.

Nelson, C. E., S. J. Goldberg, L. Wegley Kelly, A. F. Haas, J. E. Smith, F. Rohwer, and C. A. Carlson. 2013. Coral and macroalgal exudates vary in neutral sugar composition and differentially enrich reef bacterioplankton lineages. The ISME journal.

Preininger, C., I. Klimant, and O. S. Wolfbeis. 1994. Optical-fiber sensor for biological oxygen demand. Analytical Chemistry 66:1841-1846.

Price, N. 2010. Habitat selection, facilitation, and biotic settlement cues affect distribution and performance of coral recruits in French Polynesia. Oecologia 163:747-758.

Rohwer, F., M. Breitbart, J. Jara, F. Azam, and N. Knowlton. 2001. Diversity of bacteria associated with the Caribbean coral Montastraea franksi. Coral Reefs 20:85-91.

Rohwer, F., V. Seguritan, F. Azam, and N. Knowlton. 2002. Diversity and distribution of coral-associated bacteria. Marine Ecology-Progress Series 243:1-10. 
Rohwer, F., M. Youle, and D. Vosten. 2010. Coral reefs in the microbial seas. Plaid Press, United States.

Sandin, S. A., J. E. Smith, E. E. DeMartini, E. A. Dinsdale, S. D. Donner, A. M. Friedlander, T. Konotchick, M. Malay, J. E. Maragos, D. Obura, O. Pantos, G. Paulay, M. Richie, F. Rohwer, R. E. Schroeder, S. Walsh, J. B. C. Jackson, N. Knowlton, and E. Sala. 2008. Baselines and degradation of coral reefs in the northern Line Islands. PLoS One 3.

Smith, J. E., M. Shaw, R. A. Edwards, D. Obura, O. Pantos, E. Sala, S. A. Sandin, S. Smriga, M. Hatay, and F. L. Rohwer. 2006. Indirect effects of algae on coral: algae-mediated, microbe-induced coral mortality. Ecology Letters 9:835-845.

Spencer, C. P. 1952. On the use of antibiotics for isolating bacteria-free cultures of marine phytoplankton organisms. Journal of the Marine Biological Association of the United Kingdom 31:97-106.

Thurber, R. V., D. Willner-Hall, B. Rodriguez-Mueller, C. Desnues, R. A. Edwards, F. Angly, E. Dinsdale, L. Kelly, and F. Rohwer. 2009. Metagenomic analysis of stressed coral holobionts. Environmental Microbiology 11:2148-2163.

Vermeij, M. J. A. and S. A. Sandin. 2008. Density-dependent settlement and mortality structure the earliest life phases of a coral population. Ecology 89:1994-2004.

Vermeij, M. J. A., I. van Moorselaar, S. Engelhard, C. Hornlein, S. M. Vonk, and P. M. Visser. 2010. The effects of nutrient enrichment and herbivore abundance on the ability of turf algae to overgrow coral in the Caribbean. PLoS One 5.

Wangpraseurt, D., M. Weber, H. Roy, L. Polerecky, D. de Beer, Suharsono, and M. M. Nugues. 2012. In Situ Oxygen Dynamics in Coral-Algal Interactions. PLoS One 7.

Wild, C., W. Niggl, M. S. Naumann, and A. F. Haas. 2010. Organic matter release by Red Sea coral reef organisms-potential effects on microbial activity and in situ $\mathrm{O}(2)$ availability. Marine Ecology-Progress Series 411:61-71.

Wild, C., M. Rasheed, U. Werner, U. Franke, R. Johnstone, and M. Huettel. 2004. Degradation and mineralization of coral mucus in reef environments. Marine Ecology-Progress Series 267:159-171.

Zobell, C. E. and D. Q. Anderson. 1936. Observations on the multiplication of bacteria in different volumes of stored sea water and the influence of oxygen tension and solid surfaces. Biological Bulletin 71:324-342. 


\section{Figure 1}

Schematic of SOOpR system.

A) Outer components of system. G11 camera in underwater housing equipped with 530 long pass emission filter. Flash from the camera is coupled to LED bank via a fiber optic cable. Underwater strobes housing three tri-star LED covered by 470 short pass excitation filter. B) Inner components used for optical triggering. Camera flash fiber-optically coupled to photo detector to convert the light signal from the flash into an electrical signal, which triggers the camera axe. The camera axe then outputs a signal to turn on the LED bank allowing for excitation of the system. 
Fiber Optic Cable

A)

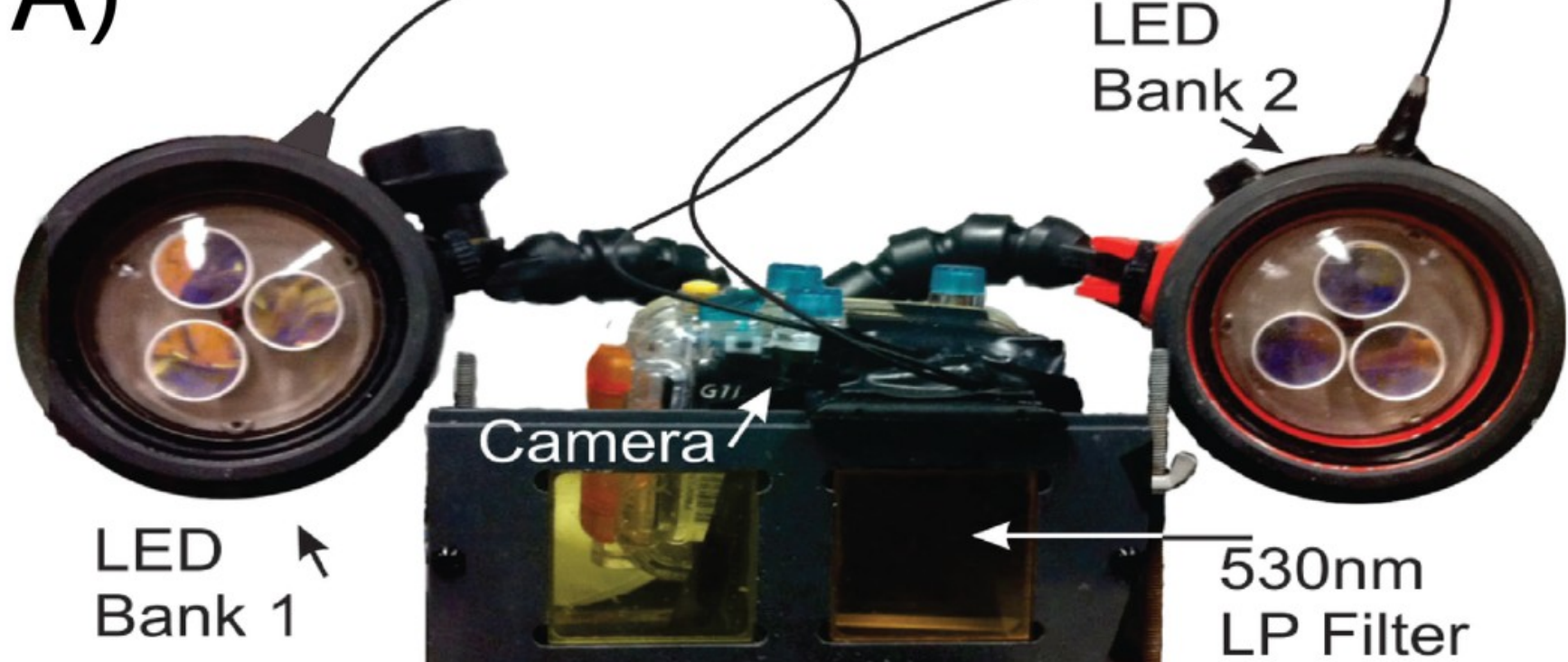

LED flash synchronization

B)

Canon G-11 camera

CHDK operating sys.
Time-lapse script

\section{Built-in flash}

Fiber optic cable

Flash unit

LED bank
Camera Axe 5

flash controller
Photo diode flash detector 


\section{Figure 2}

Dissolved oxygen draw down by four single bacterial strains isolated from $M$. annularis and exposed to turf exudate.

$\mathrm{n}=8$ replicates. Con $=$ control. ${ }^{* *}$ significantly higher oxygen draw down $(\mathrm{P}<0.01), \alpha=0.05$. Error bars represent $\pm \mathrm{SE}$.

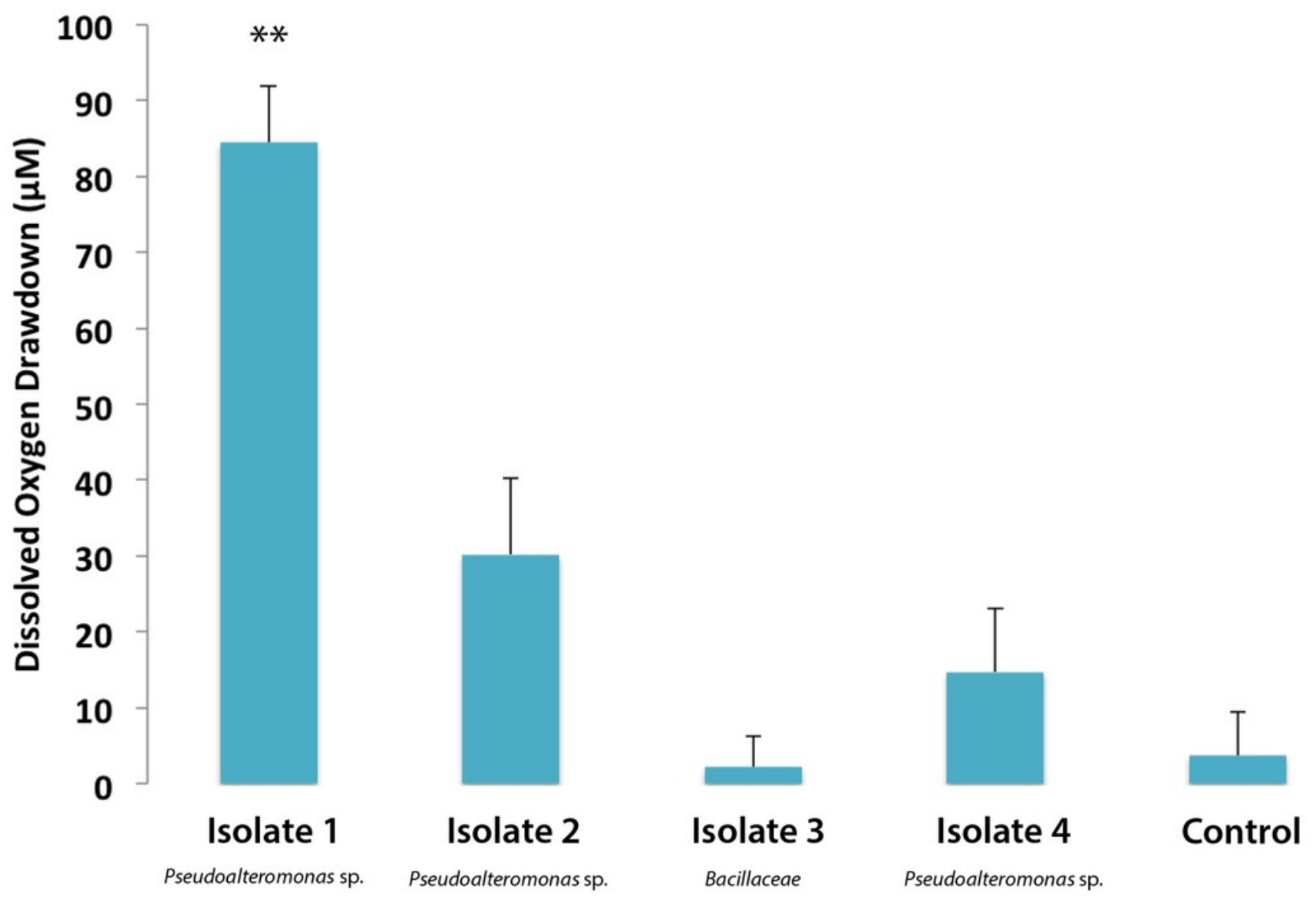




\section{Figure 3}

Dissolved oxygen draw down by bacterial communities cultured from turf, coral and CCA.

All bacterial communities exposed to $0.22 \mu \mathrm{m}$ - filtered turf exudate. Microbial communities cultured from turf, CCA, and corals maintained in an aquaria for $\sim 6$ months. No significant difference in oxygen drawdown by different communities of bacteria ( $p>0.05$ ). Error bars represent \pm SE.

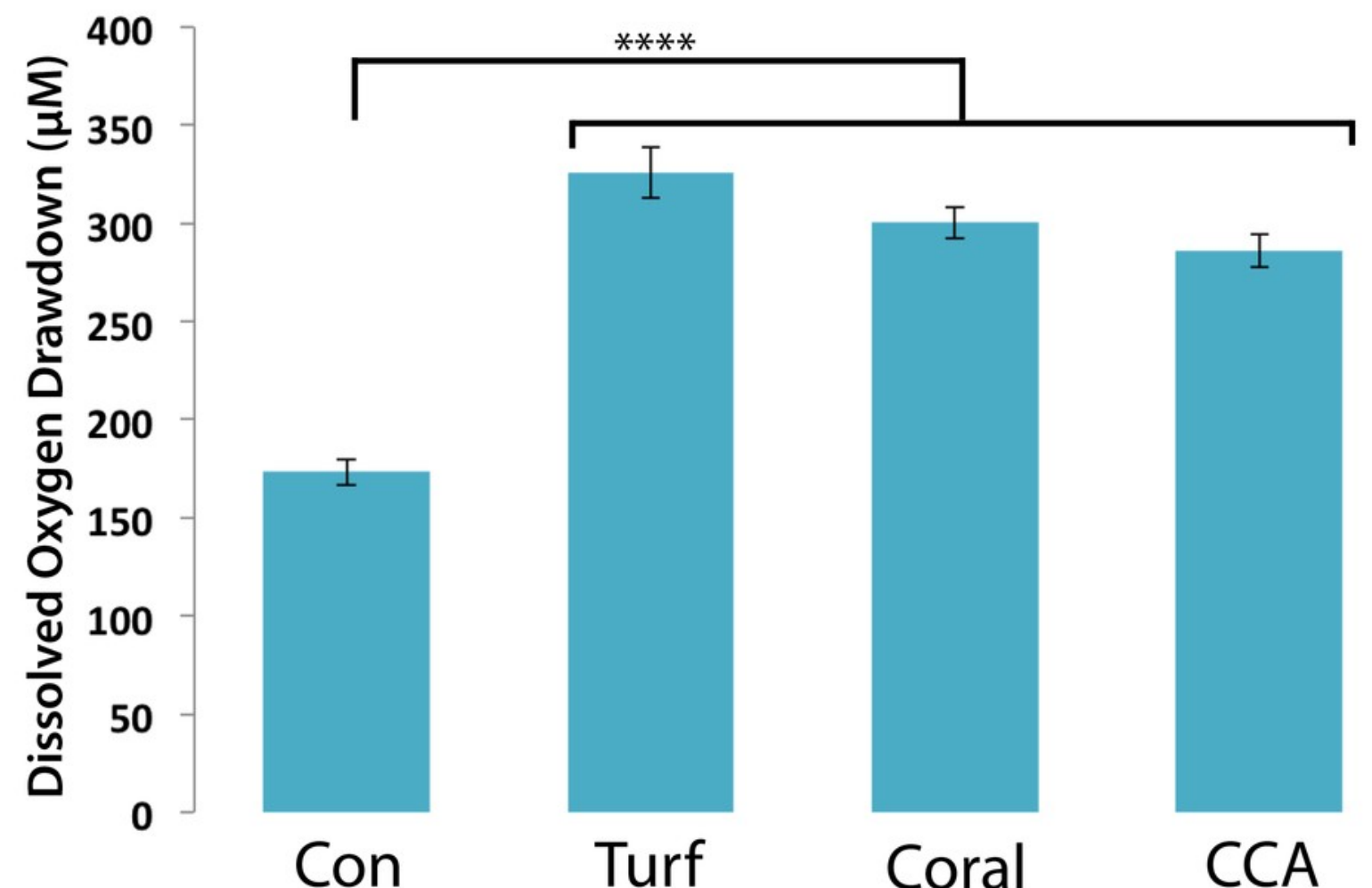




\section{Figure 4}

Experimental BOD plates.

$\mathrm{T}_{\text {initial }}$ and $\mathrm{T}_{\text {final }}$ (after 7 hours) images of BOD plates in turf exudate, CCA exudate, and seawater incubations. Bacteria inoculum distributed in checkerboard pattern starting with first well having bacteria. Increase in red luminescent signal correlates with decrease in oxygen concentration.

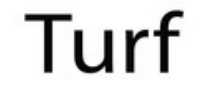

CCA
Seawater

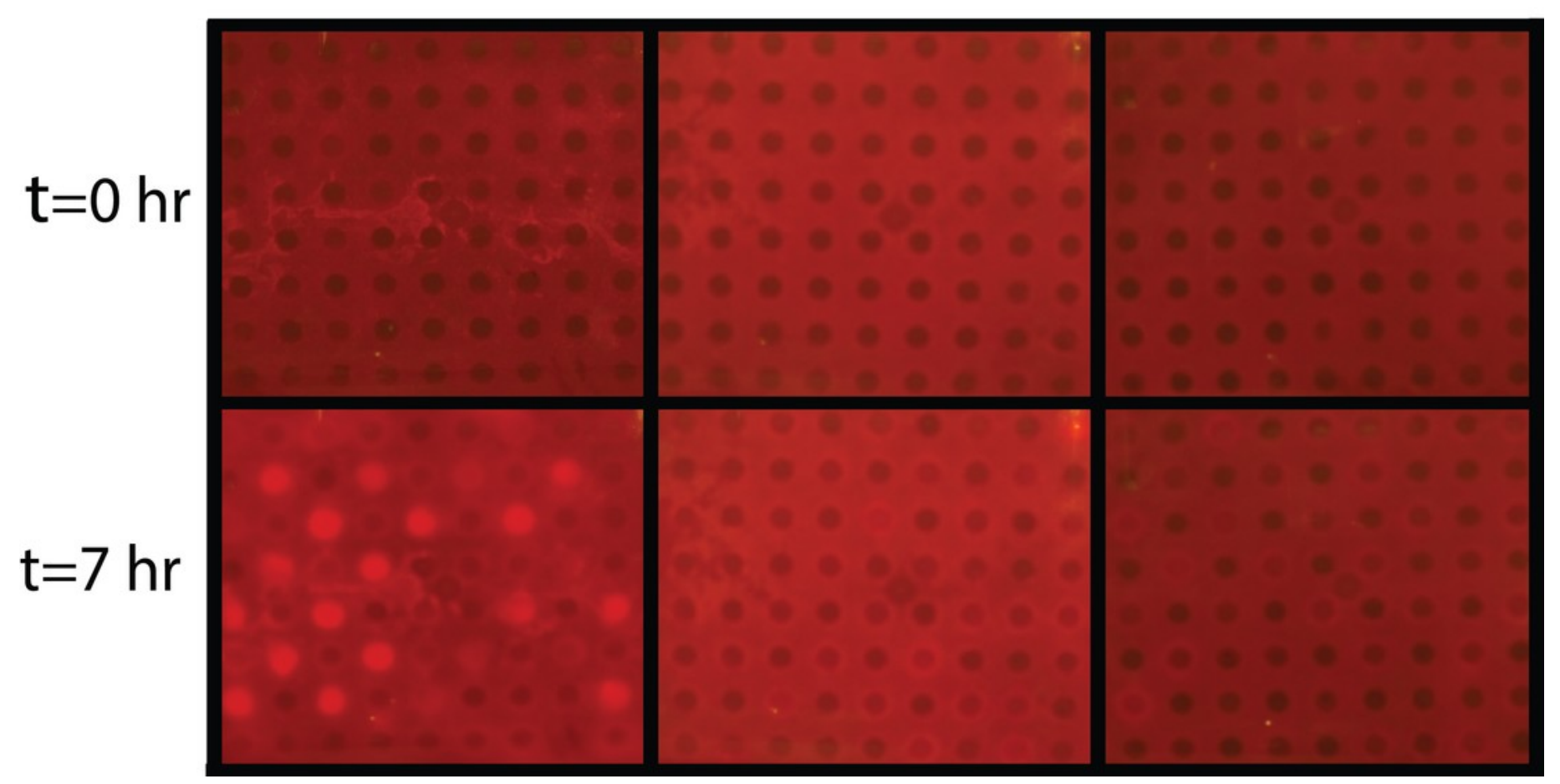




\section{Figure 5}

Dissolved oxygen draw down by coral-associated bacteria when exposed to different algal exudate treatments.

Microbial communities cultured from a) Montastraea annularis ( $\mathrm{n}=30)$ and b) Mussismilia hispida $(n=12)$ when exposed to turf algae exudate, crustose coralline algae exudate and seawater. Mic and Con correspond to wells with and without bacteria in the agar, respectively. $* * * *=\mathrm{P}<0.0001, * * *=\mathrm{P}$ $<0.001,{ }^{* *}=\mathrm{P}<0.01$ at $\alpha=0.05$. Error bars represent $\pm \mathrm{SE}$.

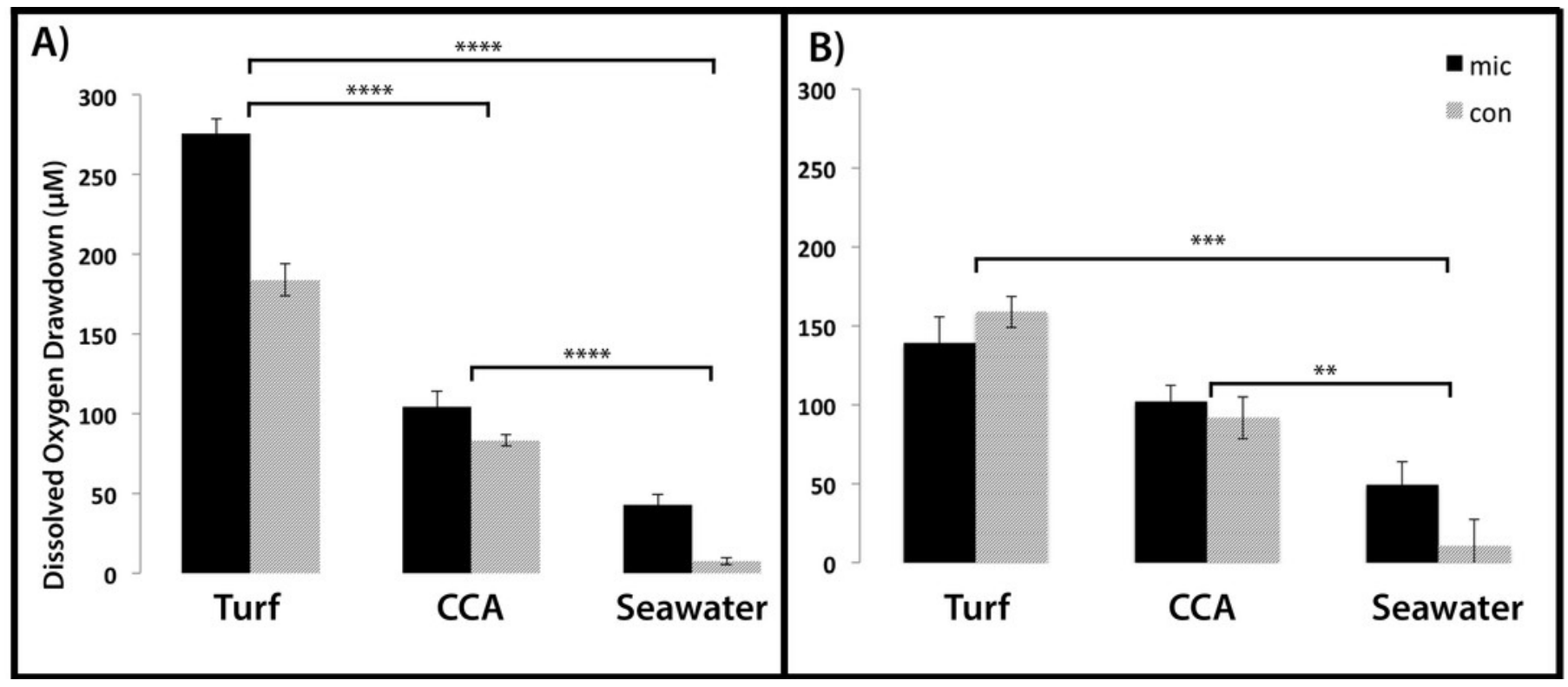

